\title{
MELCOR Accident Analysis for ARIES-ACT
}

\section{0th Topical Meeting on the Technology of Fusion Energy}

\author{
Paul W. Humrickhouse \\ Brad J. Merrill
}

The INL is a

U.S. Department of Energy

National Laboratory

operated by

Battelle Energy Alliance

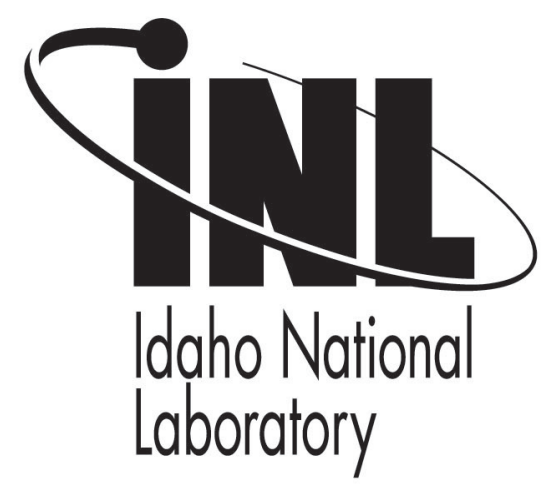

This is a preprint of a paper intended for publication in a journal or proceedings. Since changes may be made before publication, this preprint should not be cited or reproduced without permission of the author. This document was prepared as an account of work sponsored by an agency of the United States Government. Neither the United States Government nor any agency thereof, or any of their employees, makes any warranty, expressed or implied, or assumes any legal liability or responsibility for any third party's use, or the results of such use, of any information, apparatus, product or process disclosed in this report, or represents that its use by such third party would not infringe privately owned rights. The views expressed in this paper are not necessarily those of the United States Government or the sponsoring agency. 


\title{
MELCOR ACCIDENT ANALYSIS FOR ARIES-ACT
}

\author{
Paul W. Humrickhouse, Brad J. Merrill
}

Idaho National Laboratory, PO box 1625 MS 3840, Idaho Falls, ID 83415, paul.humrickhouse@inl.gov

We model a loss of flow accident (LOFA) in the ARIES-ACT1 tokamak design. ARIES-ACT1 features an advanced SiC blanket with $\mathrm{LiPb}$ as coolant and breeder, a helium cooled steel structural ring and tungsten divertors, a thin-walled, helium cooled vacuum vessel, and a room temperature water-cooled shield outside the vacuum vessel. The water heat transfer system is designed to remove heat by natural circulation during a LOFA. The MELCOR model uses time-dependent decay heats for each component determined by 1-D modeling. The MELCOR model shows that, despite periodic boiling of the water coolant, that structures are kept adequately cool by the passive safety system.

\section{INTRODUCTION}

The ARIES-ACT (Ref. 1) design study will ultimately comprise four advanced tokamak designs representing the "four corners" of plasma physics and engineering/technology design space, in which each is either conservative or aggressive. Identification of these design points is made possible by the ARIES Systems Code, ${ }^{2}$ which is equipped with costing algorithms that allow for determination of the effect of various design parameters on the cost of electricity generated by the reactor. The first of these four design points, ARIESACT1, which features aggressive physics and engineering, is the subject of this paper.

As with previous ARIES designs, ${ }^{3-4}$ safety considerations play a role in the design, and safety analysis of the final design is an integral part of the project. As a first step, we consider here the implications of a loss of flow accident (LOFA) resulting from a loss of offsite power or long term station blackout. It is desired that the passive safety systems of ARIES-ACT prevent any structural damage or melting due to decay heat no matter how long the blackout. Other accident scenarios, such as loss of coolant (including scenarios involving $\mathrm{LiPb}$-water interactions) will be considered in future work.

ARIES-ACT1 resembles in some ways the previous ARIES-AT (advanced tokamak) design ${ }^{5}$, and it uses a similar $\mathrm{SiC}$ blanket concept with $\mathrm{LiPb}$ as coolant and breeder. The LiPb flows upward through a thin outer annular shell in each blanket (one inboard and two outboard) at high velocity to provide sufficient cooling for the hot first wall, and then returns flowing downward at lower velocity through a larger center channel (Figure 1). Significant differences from ARIES-AT include a heliumcooled tungsten-alloy divertor, and a helium-cooled steel structural ring, which supports the in-vessel components and acts as a high temperature $\left(675^{\circ} \mathrm{C}\right)$ shield. These and other features of the ARIES-ACT1 design are described in Ref. 6.

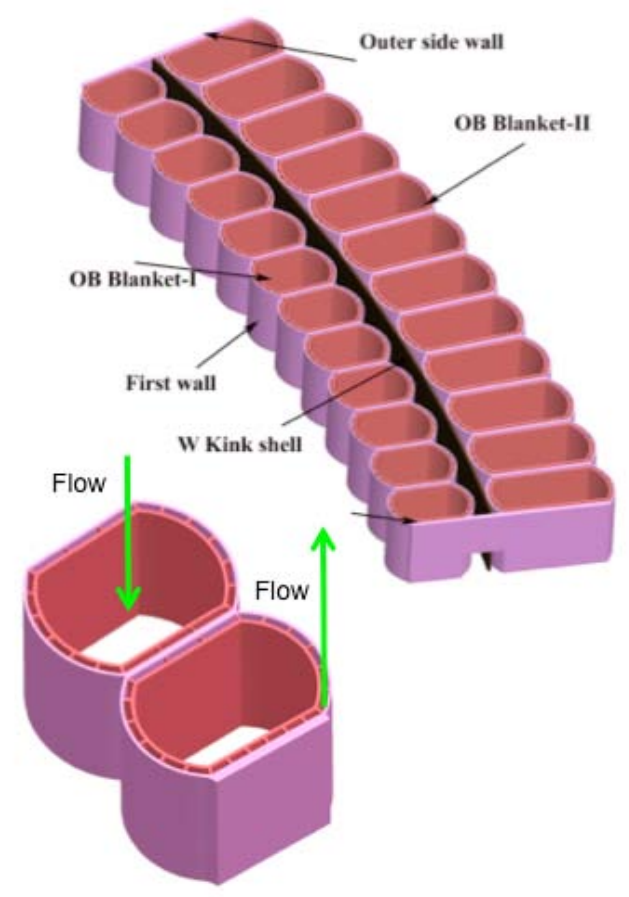

Fig. 1. ARIES-ACT1 outboard blanket and $\mathrm{LiPb}$ flow paths.

The ARIES-AT vacuum vessel was a thick (25-40 $\mathrm{cm})$, water-cooled, low activation ferritic steel structure that also served as a neutron shield for the magnets. For ARIES-ACT, concerns about tritium permeation through the vacuum vessel wall at high temperature and the 
resulting possibility of a large inventory of tritium in the vacuum vessel water coolant prompted an investigation of helium-cooled designs. These did not adequately shield the magnets, so the design was modified to serve each of these needs with a different component: a thin $(5-10 \mathrm{~cm})$ walled, high temperature, helium cooled vacuum vessel, and a room temperature water-cooled shield for the magnets outside the vacuum vessel. Both the vacuum vessel and water-cooled shield are constructed of a new reduced activation bainitic steel, 3Cr-3WV (Ref. 7). The arrangement of these structures is shown in Figure 2.

Similarly to previous ARIES designs ${ }^{4}$, passive decay heat removal is achieved by natural circulation in the water coolant in the event of loss of flow. The heat exchanger for this system is located on the roof of the confinement building, and is thus able to transfer heat from the circulating water to ambient air.

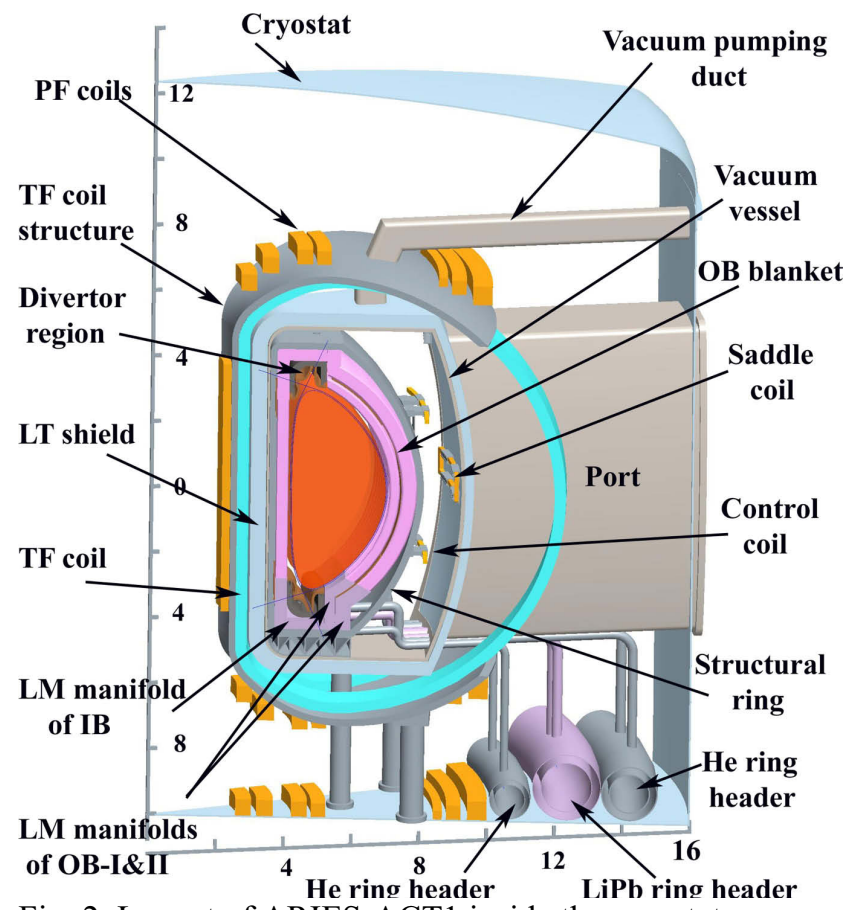

Fig. 2. Layout of ARIES-ACT1 inside the cryostat.

\section{MELCOR MODEL}

In order to determine whether natural circulation of the water is sufficient to remove decay heat during a LOFA, a MELCOR model of ARIES-ACT1 has been developed. MELCOR is a code developed at Sandia National Laboratories ${ }^{8}$, originally for analysis of light water fission reactor accidents. A series of modified versions have been developed at INL for application to fusion accidents. MELCOR 1.8.5 (Ref. 9) was unique among these in that the default water coolant could be replaced by a number of others relevant for fusion, including $\mathrm{LiPb}$, a feature as yet unavailable in the other fusion versions of the code.

Though MELCOR 1.8.5 can use a variety of working fluids, as with all versions of MELCOR, only one such fluid may be used in a given problem (not including ideal gases). This presents some obvious challenges when modeling the present ARIES-ACT1 design, since there is no way to include both $\mathrm{LiPb}$ and water coolants. In order to overcome this, the present model is actually a scripted coupling of two separate MELCOR models, one containing the $\mathrm{LiPb}$ and helium cooled components and loops, and the other containing the water cooled shield and associated heat transfer system. The two models run concurrently, and information is passed between the two in the same manner used internally in the code; the temperatures of four heat structures of one model are used to update the four heat structures in the corresponding model, and then the heat flux from this model is used to update the temperatures of the original four structures for that time interval. Conservation of energy is verified through output information. An additional benefit of this method is that it essentially parallelizes the problem, and a modest improvement in the wall clock time required to complete the simulation is realized.

The MELCOR model of ARIES-ACT1 comprises $1 / 3$ of the tokamak. The primary heat structures and fluid volumes included in the $\mathrm{LiPb} / \mathrm{helium}$ system model include the $\mathrm{SiC}$ walls and $\mathrm{LiPb}$ flow channels of the three (one inboard and two outboard) blankets, the upper and lower divertors each with two plates and helium coolant, the steel structural ring (high temperature shield) and helium coolant, and the double walled vacuum vessel segments representing the inboard, outboard, top, and bottom of the vessel. These components are shown in the schematic in Figure 3. The ex-vessel heat transfer systems for $\mathrm{LiPb}$ and helium are included but not shown in the figure; neither does it include the water-cooled shield and associated heat transfer system, which are modeled by a separate input file as described above. The vacuum vessel, which operates at significantly lower temperature than the other helium cooled components (high temperature shield and divertor), is cooled by a separate helium loop as shown in figures 2 and 3 . In the present model, the divertors and high temperature shield are cooled by the same loop. These may be split as the design evolves to allow for better control of the temperatures of these components.

After a short $(1000 \mathrm{~s})$ period that is modeled to establish the appropriate steady state temperatures of these components, forced cooling is lost in all loops. Beginning at this time, all the above-mentioned components generate decay heat. The decay heats used in the present model are based on a simplified 1-D MCNP analysis; the final safety analysis will use a more recent comprehensive 3-D model ${ }^{10}$. Decay heats for outboard components are shown in Figure 4. These are input for 


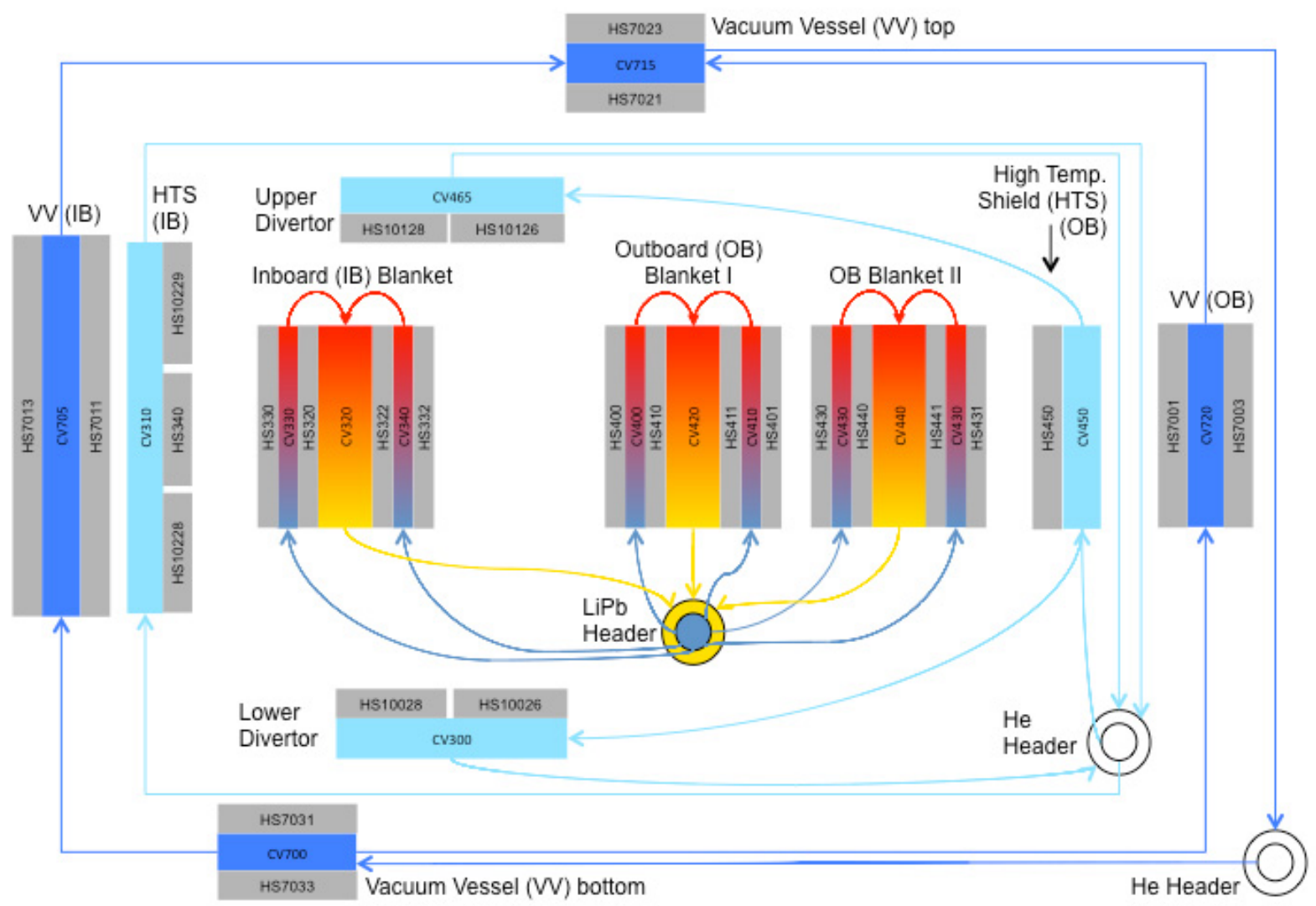

Fig. 3. A schematic of the primary components of the LiPb and He cooled systems in ARIES-ACT1 as modeled in MELCOR. Three coolant loops are present: two helium loops (one for the highest temperature components, the divertors and structural ring, and one for the VV), and the LiPb loop through the blankets. Solid structures are labeled with the prefix "HS" and coolant volumes with "CV"; arrows indicate the flow direction. Note that the ex-VV heat transfer systems and the water-cooled shield and associated water systems are not shown here.

each component, as a function of time, in the MELCOR model. Though the decay heat drops significantly in the first hour in the $\mathrm{SiC}$ structures, they continue to be heated by the decay heat from the $\mathrm{LiPb}$, which does not. The kink shell, despite its comparatively small volume, contributes a larger amount of decay heat and therefore needs to be accounted for.

\section{RESULTS AND DISCUSSION}

At the initiation of the accident, decay heating of structures drives a continually increasing flow rate of water through the water-cooled shield by natural convection. About eight hours into the accident, when it has reached $\sim 5 \mathrm{~kg} / \mathrm{s}$, water begins to boil. The boiling causes a large spike in the flow rate to the heat transfer system, but the steam condenses and returns through the same path to the shield, abruptly cooling the structures. This periodic (initially about every two hours; the period grows longer over time) boiling and condensing continues throughout the transient, with the flow rate remaining more or less constant in between boiling events at $\sim 5 \mathrm{~kg} / \mathrm{s}$. It is not entirely clear how accurate MELCOR is in modeling this phenomenon, though we note that it has been benchmarked and used extensively for PWR and BWR accident analyses that involve boiling and condensation of water.

Design changes are being investigated that would eliminate the periodic boiling, though it does not detract from the ability of the system to passively cool in-vessel structures, as evidenced by their temperatures shown in Figure 6 . Here it can be seen that the temperatures of the divertors, first wall (inboard and outboard), and structural ring (high temperature shield) do not increase significantly above their normal operating temperatures. All structure temperatures have peaked and begin decreasing again within the first half-day after loss of flow. Since the decay heats are continually decreasing, temperatures decrease continually after peaking as well; the models described here were run to seven days. 

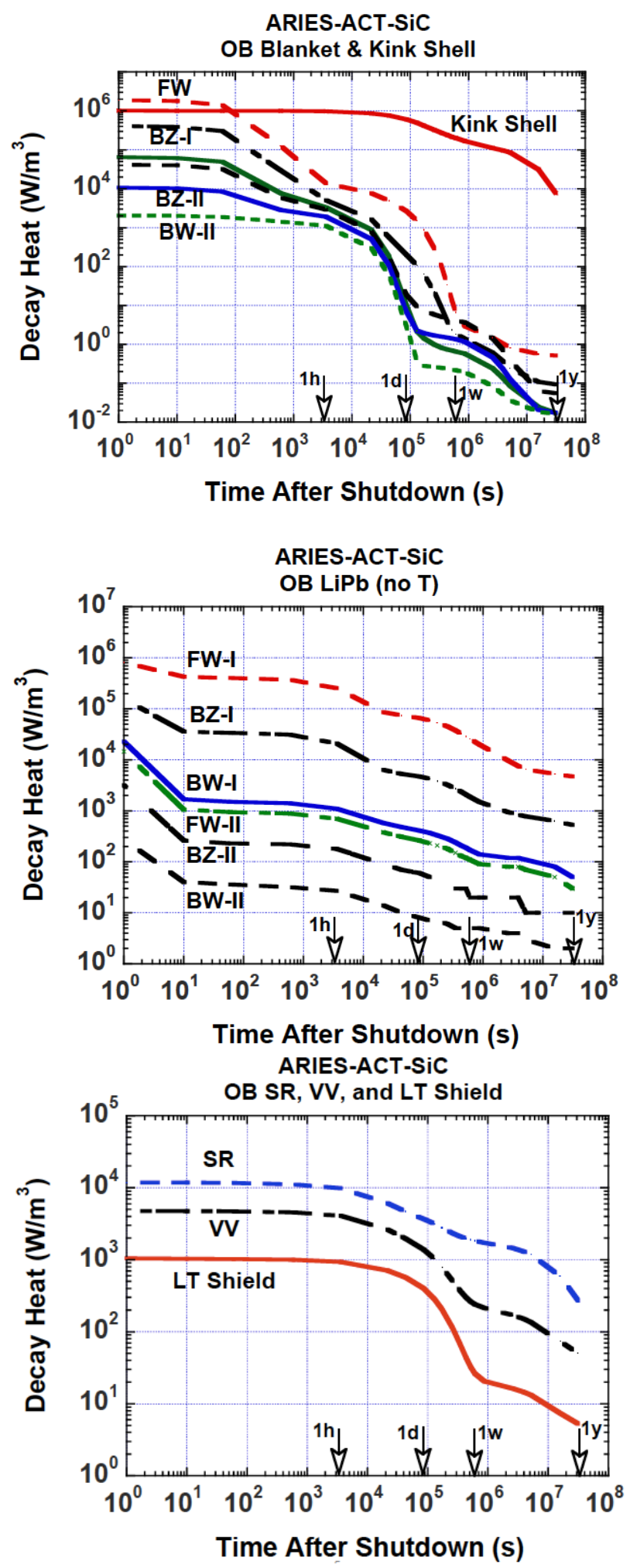

Fig. 4. Decay heat in ARIES-ACT1 outboard components as a function of time: blanket structure ( $\mathrm{SiC}$ and kink shell, top), blanket $\mathrm{LiPb}$ (middle), and structural ring, vacuum vessel, and water cooled shield (bottom) ${ }^{10}$.

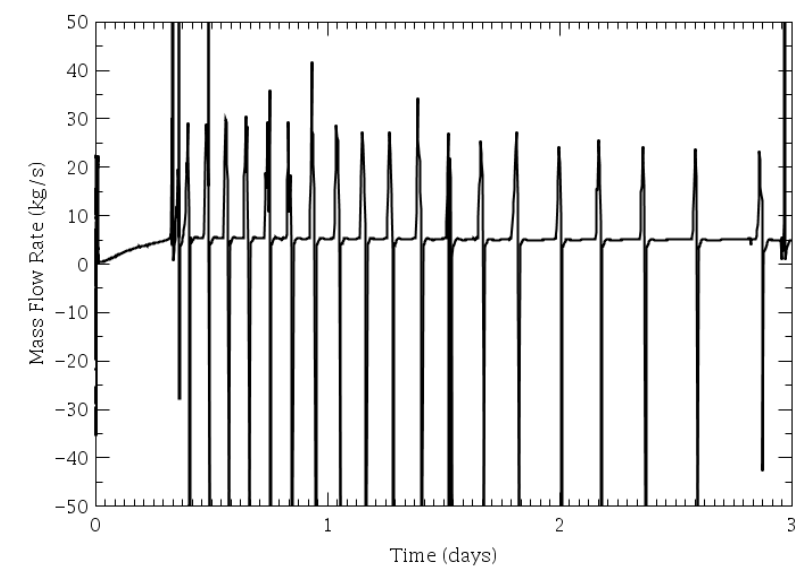

Fig. 5. Mass flow rate of water from the water-cooled shield outlet to the heat transfer system.

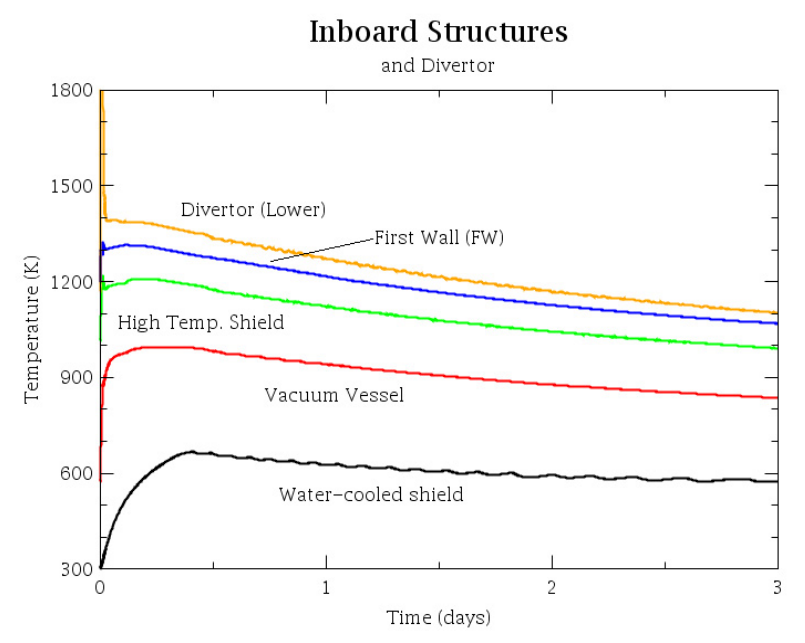

Outboard Structures

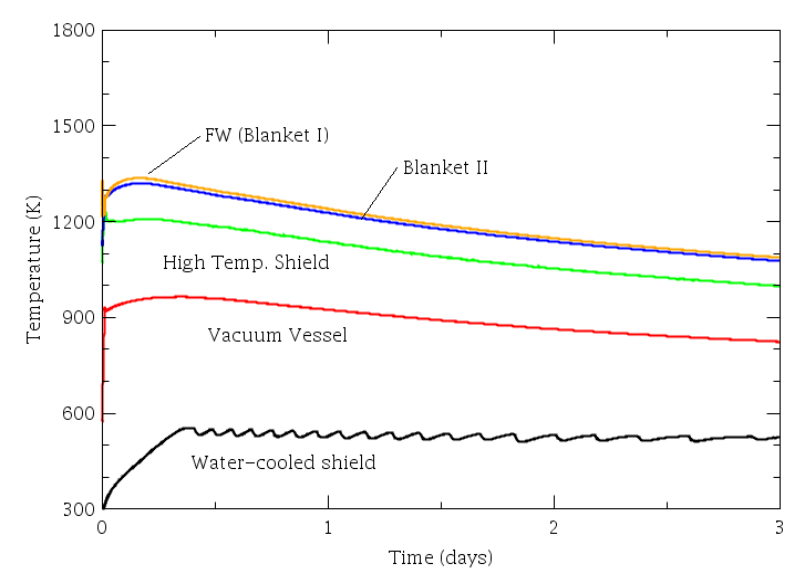

Fig. 6. Inboard (above) and outboard (below) structure temperatures during LOFA. 
The effect of the periodic boiling of the water coolant is evident in the oscillating temperature of the inboard and outboard water-cooled shield after this time. These structures are more distant from the top of the vessel where the boiling occurs, so these oscillations are smoothed somewhat. Though the temperatures themselves are not a concern for $3 \mathrm{Cr}-3 \mathrm{WV}$ steel, it should be noted that the normal operating temperature of the water-cooled shield in this design is $300 \mathrm{~K}$, at which it may be affected by shifts in the ductile-to-brittle transition temperature under irradiation. This may be acceptable since it is not intended to serve as a vacuum or pressure vessel; however, the assumption that stresses occurring in the shield are ignorable may warrant some further investigation in light of the fact that there are temperature differences of several hundred degrees $\mathrm{K}$ across it, and the fact that it must contain water that boils during the LOFA, which also creates some cyclic changes in temperature. An increase in the volume of water in this system to avoid boiling altogether will also be investigated.

\section{FUTURE WORK}

A more comprehensive safety analysis is planned for ARIES-ACT1 and the other ARIES-ACT design variants, which will be detailed in a subsequent publication. These may include analysis of a loss of coolant accident (LOCA), in which release of the release of radioactive materials including tritium must be considered, and chemical interactions between $\mathrm{LiPb}$ and water. The multiple coolants and coolant loops present in ARIESACT imply a number of different possible LOCA scenarios. The most challenging of these is a water LOCA in which the LiPb system remains intact; in this case, the passive heat removal provided by the water is lost, but the $\mathrm{LiPb}$ continues to heat surrounding structures. Some additional modifications to the MELCOR model will be necessary to consider this case. As a simplification and measure of conservatism in the present model, the outside of the water-cooled shield is treated as an adiabatic boundary. In a water LOCA, which disables the passive heat removal mechanism, heat transfer through this boundary is the only way to transfer it away from in-vessel components. In ARIES-ACT, the surface is covered with a multi-layer superinsulation. The superinsulation consists of multiple layers (e.g. 10-15, Ref. 11) across which heat must radiate. Heat transfer is reduced depending on the number of layers $N$ according to:

$$
q^{\prime \prime}=\frac{\varepsilon}{N+1} \sigma\left(T_{H}^{4}-T_{L}^{4}\right)
$$

In the absence of water cooling, it is not clear whether sufficient heat would be transferred across the superinsulation to sufficiently cool structures. It might also act as a barrier to conductive and convective heat transfer that may not be easily overcome by other strategies for heat removal by these mechanisms, such as gas injection into the cryostat.

\section{REFERENCES}

1. F. NAJMABADI et al., "Re-examination of Visions for Tokamak Power Plants: ARIES-ACT Study," presented at 20th ANS Topical Meeting on the Technology of Fusion Energy, Nashville, TN, 2012.

2. L. C. CARLSON et al., "Development, Visualization, and Application of the ARIES Systems Code," IEEE Trans. Plasma Sci., 40(3), 552 (2012).

3. D. A. PETTI et al., "ARIES-AT Safety Design and Analysis," Fusion Eng. Des., 80, 111 (2006).

4. B. J. MERRILL et al., "Safety Assessment of the ARIES Compact Stellarator Design," Fusion Sci. Technol., 54, 838 (2008).

5. F. NAJMABADI and THE ARIES TEAM, "Overview of the ARIES-AT Advanced Tokamak, Advanced Technology Fusion Power Plant," Fusion Eng. Des., 80, 3 (2006).

6. M. TILLACK et al., "ARIES-ACT1 Power Core Engineering," TOFE 2012 Proceedings, Fusion Sci. Technol., 64, (2013).

7. L. EL-GUEBALY et al., "Design Challenges and Activation Concerns for ARIES Vacuum Vessel," TOFE 2012 Proceedings, Fusion Sci. Technol., 64, (2013).

8. R. O. GAUNTT et al., "MELCOR Computer Code Manuals Vol. 1: Primer and Users' Guide Version 1.8.5," NUREG/CR-6119, Vol. 1, Rev. 2, Sandia National Laboratory (2000).

9. B. J. MERRILL et al., "Modifications to the MELCOR Code for Application in Fusion Accident Analyses," Fusion Eng. Des., 51-52, 555 (2000).

10. L. MYNSBERGE, A. JABER, and L. ELGUEBALY, "Three-Dimensional Evaluation of Tritium Breeding Ratio, Nuclear Heating Distribution, and Neutron Wall Loading Profile for ARIES-ACT1 ( $\mathrm{SiC} / \mathrm{LiPb})$ Design," University of Wisconsin Fusion Technology Institute report UWFDM-1414, December 2012.

11. A. PONCET and V. PARMA, "Series-produced Helium II Cryostats for the LHC Magnets: Technical Choices, Industrialisation, Costs," AIP Conf. Proc., 985, 739 (2008). 